\title{
A comprehensive review of the PARTNER trial
}

\author{
Lars G. Svensson, MD, PhD, ${ }^{\mathrm{a}}$ Murat Tuzcu, MD, ${ }^{\mathrm{b}}$ Samir Kapadia, MD, ${ }^{\mathrm{b}}$ Eugene H. Blackstone, MD, ${ }^{\mathrm{a}, \mathrm{c}}$ \\ Eric E. Roselli, MD, ${ }^{a}$ A. Marc Gillinov, MD, ${ }^{a}$ Joseph F. Sabik III, MD, ${ }^{a}$ and Bruce W. Lytle, MD ${ }^{\mathrm{a}}$
}

Objective: Percutaneous transcatheter aortic valve replacement was introduced in 2002, but its effectiveness remained to be assessed.

\begin{abstract}
Methods: A prospective, randomized trial (the Placement of Aortic Transcatheter Valves, or PARTNER) was designed with 2 arms: PARTNER A $(n=699)$ for high-risk surgical patients (Society of Thoracic Surgeons score $>10 \%$, surgeon assessed risk of mortality $>15 \%)$ and PARTNER B $(\mathrm{n}=358$, patients inoperable by assessment of 2 surgeons). PARTNER A patients were divided into femoral artery access transcatheter aortic valve replacement or none $(n=207)$, and then randomized to open aortic valve replacement $(n=351)$ or device $\left(\mathrm{n}=348\right.$ ). Inclusion criteria included valve area $<0.8 \mathrm{~cm}^{2}$, gradient $>40 \mathrm{~mm} \mathrm{Hg}$ or peak $>64 \mathrm{~mm} \mathrm{Hg}$, and survival $>1$ year. The end point of the study was 1 -year mortality.

Results: Thirty-day mortality for PARTNER A was 3.4\% for transcatheter aortic valve replacement and $6.5 \%$ for aortic valve replacement; 1 -year mortality was $24.2 \%$ and $26.8 \%$, respectively ( $P=.001$ for noninferiority). The respective prevalence of stroke was $3.8 \%$ and $2.1 \%(P=.2)$, although for all neurologic events, the difference between transcatheter aortic valve replacement and aortic valve replacement was significant $(P=$ .04 ), including $4.6 \%$ for femoral artery access transcatheter aortic valve replacement versus $1.4 \%$ for open aortic valve replacement $(P=.05)$. For PARTNER B-transcatheter aortic valve replacement versus medical treatment-30-day mortality was $5.0 \%$ versus $2.8 \%(P=.41)$, and at 1 year, mortality was $30.7 \%$ versus $50.7 \%(P<.001)$, respectively. Hospitalization cost of transcatheter aortic valve replacement for PARTNER B was $\$ 78,542$, or $\$ 50,200$ per year of life gained. Analysis of PARTNER A strokes showed that hazard with transcatheter aortic valve replacement peaked early, but thereafter remained constant in relation to aortic valve replacement. Two-year PARTNER A data showed paravalvular regurgitation was associated with increased mortality, even when mild $(P<.001)$. Continued access to transapical transcatheter aortic valve replacement $(\mathrm{n}=853$ ) showed a mortality of $8.2 \%$ and decline in strokes to $2.0 \%$. Of the 1801 Cleveland Clinic patients reviewed to December 2010, $214(12 \%)$ underwent transcatheter aortic valve replacement with a mortality of $1 \%$; in 2011, 105 underwent transcatheter aortic valve replacement: 34 transapical aortic valve replacement, with no deaths, and 71 femoral artery access aortic valve replacement with 1 death.
\end{abstract}

Conclusions: The PARTNER A and B trials showed that survival has been remarkably good, but stroke and perivalvular leakage require further device development. (J Thorac Cardiovasc Surg 2013;145:S11-6)

H.R. Andersen first obtained a patent for an intra-aortic valve metal-stent balloon expandable valve with internal biologic leaflets. ${ }^{1-6}$ Subsequently, Cribier, Leon, and Moses

\footnotetext{
From the Department of Thoracic and Cardiovascular Surgery ${ }^{\mathrm{a}}$ and Department of Cardiovascular Medicine, ${ }^{\mathrm{b}}$ Heart and Vascular Institute; and Department of Quantitative Health Sciences, ${ }^{c}$ Research Institute, Cleveland Clinic, Cleveland, Ohio.

Dr Svensson holds stock in Cardiosolutions and ValveXchange and receives royalties from Post-Thorax. Dr Roselli is a consultant for Medtronic and Edwards Lifesciences, and is a teacher and speaker for Cook Medical and Terumo Medical. Dr Gillinov is a consultant for Edwards Lifesciences and Onyx Lifesciences, and receives research support from St. Jude Medical and Medtronic. Dr Sabik is a consultant for Medtronic and ValveXchange, and receives lecture fees from Edwards Lifesciences.

Drs Tuzcu, Kapadia, Blackstone, and Lytle have nothing to disclose with regard to commercial support.

Read at The American Association for Thoracic Surgery Aortic Symposium, New York, New York, April 26-27, 2012.

Received for publication April 26, 2012; revisions received Aug 10, 2012; accepted for publication Nov 28, 2012

Address for reprints: Lars G. Svensson, $\mathrm{MD}, \mathrm{PhD}$, The Aortic Center and Heart and Vascular Institute, Cleveland Clinic, 9500 Euclid Ave, Desk J4-1, Cleveland, OH 44915 (E-mail: svenssl@ccf.org).

$0022-5223 / \$ 36.00$

Copyright (c) 2013 by The American Association for Thoracic Surgery

http://dx.doi.org/10.1016/j.jtcvs.2012.11.051
}

persisted with developing the technology using a femoral transvenous approach. ${ }^{1-6}$ A transapical (TA) transcatheter aortic valve replacement (TAVR) approach was then developed, followed by a transarterial femoral (TF) approach and, more recently, transaortic and transaxillary approaches. Two initial feasibility trials were performed in the United States for both TA-TAVR and TF-TAVR. ${ }^{1-23}$

The PARTNER trial (Placement of Aortic Transcatheter Valves) was designed as a multicenter randomized trial comparing open standard aortic valve replacement (AVR) with TAVR in high-risk patients, and also TAVR versus standard medical treatment. ${ }^{1,2,5,6}$ In addition, cost analysis, 2-year data analysis, and stroke analysis have been done, as well as analysis of continued access for TA-TAVR. ${ }^{1,2,4,21}$

\section{METHODS}

A total of 3105 patients were presented to a Web-based review panel for potential inclusion in the trial (Figure 1). Ultimately, 12\% were enrolled; however, the number of patients reviewed at sites but not presented was 


\begin{tabular}{|c|c|}
\hline \multicolumn{2}{|c|}{ Abbreviations and Acronyms } \\
\hline AVR & $=$ aortic valve replacement \\
\hline BMI & $=$ body mass index \\
\hline COPD & $\begin{aligned}= & \text { chronic obstructive pulmonary } \\
& \text { disease }\end{aligned}$ \\
\hline FDA & $=$ Food and Drug Administration \\
\hline PART & $=$ Placement of Aortic \\
\hline & Transcatheter Valves \\
\hline STS & $=$ Society of Thoracic Surgeons \\
\hline TA & $=$ transapical \\
\hline TAVR & $\begin{aligned}= & \text { transcatheter aortic valve } \\
& \text { replacement }\end{aligned}$ \\
\hline $\mathrm{TF}$ & $=$ transarterial femoral \\
\hline
\end{tabular}

considerably higher. For example, as of December 2010 at Cleveland Clinic, we had reviewed 1801 patients who were considered potential trial participants. If patients presented for potential enrollment but clearly were not candidates based on inclusion and exclusion criteria, they were then reviewed for surgery, balloon dilatation, or medical treatment. Hence, of the 1801 patients reviewed formally and discussed at our weekly Tuesday morning meeting, 193 went on to surgery and 214 went on to enrollment into TAVR studies. During the same period, the number of patients who underwent open AVR was noted.

Briefly, PARTNER A patients were required to be high risk for conventional open valve surgery. ${ }^{1,5}$ This was determined by a minimal Society of Thoracic Surgeons (STS) score of $10 \%$ for death, and the surgeons' assessment of the risk as $>15 \%$. In addition, patients were required to have symptomatic aortic valve stenosis with an area $<0.8 \mathrm{~cm}^{2}$, and gradients either $>$ a mean of $40 \mathrm{~mm} \mathrm{Hg}$ or a peak of $64 \mathrm{~mm} \mathrm{Hg}$, the latter equivalent to a velocity of $4 \mathrm{~m} / \mathrm{sec}$ nd. The list of exclusions included recent myocardial infarction, stroke, infections, creatinine level $>3.0 \mathrm{mg} / \mathrm{dL}$, and patients not likely to survive a year. For PARTNER $\mathrm{B},{ }^{2,6}$ patients approved for the study were required to have 2 cardiac surgeons agree that they were inoperable based on a combined risk of death and irreversible severe morbidity $>50 \%$.

Data on hospital costs were also collected. After completion of the trial, patients could be enrolled in continued access to TAVR in PARTNER A and PARTNER B. Furthermore, after 1 year, surviving patients were allowed to cross over in PARTNER B. PARTNER B patients listed as having died from unknown causes underwent careful review to determine cause of death.

The trial was designed by members of the PARTNER executive committee and the sponsor (Edwards Lifesciences), with additional input and approval from the U.S. Food and Drug Administration (FDA). In June 2006, the proposal for a randomized trial with 2 arms for either inoperable or high-risk surgical patients was proposed by 3 of us (L.G.S., E.H.B., and B.W.L.) and other surgeons, with the high-risk surgical patients randomized to open AVR, TF-TAVR, or TA-TAVR. The final trial was designed based on extensive discussion, and TA-TAVR was dropped from randomization in patients with femoral access. The executive committee and principal investigators had full access to all the data after the database was locked. An independent clinical events committee arbitrated events and complications. For PARTNER B deaths and neurologic events in PARTNER A, clinical events committee records were reviewed in detail. An independent echocardiography core laboratory assessed echocardiographic outcomes.

The device used for the study consisted of a stainless steel tubular mesh stent with internal bovine pericardial leaflets (Edwards LifeSciences'
Sapien valve). The device was loaded onto an inflatable balloon within a loader. A balloon dilatation was performed first and then, when the device was positioned correctly, the balloon was inflated during rapid pacing of the heart, usually at 180 to 200 beats per minute. Transesophageal echocardiography was used to check correct position, supplemented as needed by root aortography. Technical steps for device insertion have been described previously. The study end points were 1-year survival, with documentation of complications and their effects on 1-year survival.

For PARTNER A, the trial was designed for noninferiority of TAVR versus open AVR and, furthermore, the TF-TAVR group assignment was powered to compare TF-TAVR noninferiority with open surgery. This was not done for TA-TAVR. Based on this design, 650 patients were required for PARTNER A with at least $85 \%$ power to show noninferiority of TAVR assuming a 1-year mortality of $29 \%$ for TAVR and $32 \%$ for AVR. Similarly, 450 patients were required for TF-TAVR power. For PARTNER $\mathrm{B}$, the trial was for superiority of TF-TAVR versus medical treatment in the control arm. To achieve $85 \%$ power to show superiority, 350 patients were required, assuming $37.5 \%$ mortality in the control subjects and $25 \%$ in the TAVR patients. In the case of PARTNER B, to analyze the nonprimary end point of both death and repeat hospitalization, the Finkelstein-Schoenfeld nonparametric method was used. ${ }^{20}$ To do this, all patients had multiple pairwise comparisons performed, first with respect to time to death and to repeat hospitalization, if the latter occurred.

\section{RESULTS}

For PARTNER A, 351 patients were assigned to AVR and 348 to TAVR, of whom 244 were TF-TAVR and 104 TATAVR. ${ }^{1,5}$ Variables were mostly well balanced between AVR and TAVR, and the mean STS score was $11.8 \%$. Actual AVR mortality was $8 \%$, a 0.68 observed-toexpected ratio compared with STS score. Patients in the non-TF-TAVR were considered for TA-TAVR; however, they had more previous coronary artery bypasses, percutaneous coronary interventions, cerebrovascular disease, previous carotid endarterectomies, peripheral arterial disease, porcelain aortas, radiation heart disease, and severe aortic valve stenosis, the latter a risk factor for neurologic events. Forty-two patients did not undergo treatment as assigned.

For TAVR, 3 patients died during the procedure, 16 had the procedure aborted or converted to open operation, 7 had multiple valves inserted ( 3 patients died), and another 7 were aborted because of valve embolization, for a total of 33 procedure failures $(9.5 \%)$. Thirty-day mortality for intention to treat for was $3.4 \%$ for TAVR and $6.5 \%$ for AVR $(P=.07)$; for TF-TAVR, mortality was $3.3 \%$ versus $6.2 \%$ with AVR $(P=.13)$. For TA-TAVR, 30-day mortality was $3.8 \%$ and control AVR was $7.0 \%(P=.32$, intention to treat). At 1 year, mortality was $24.2 \%$ for TAVR and $26.8 \%$ for AVR, with no significant difference, meeting noninferiority. Prevalence of neurologic events for TAVR versus AVR at 30 days was $5.5 \%$ versus $2.4 \%(P=.04)$; major strokes was $3.8 \%$ versus $2.1 \%(P=.2)$. For all neurologic events, TF-TAVR versus open AVR was $4.6 \%$ versus $1.4 \%(P=.05)$. Subgroup analysis showed that women fared better with TAVR and patients undergoing reoperations fared better with open AVR, contrary to expectations, and not fully explained. Other events included more vascular 
Symptomatic Severe Aortic Stenosis

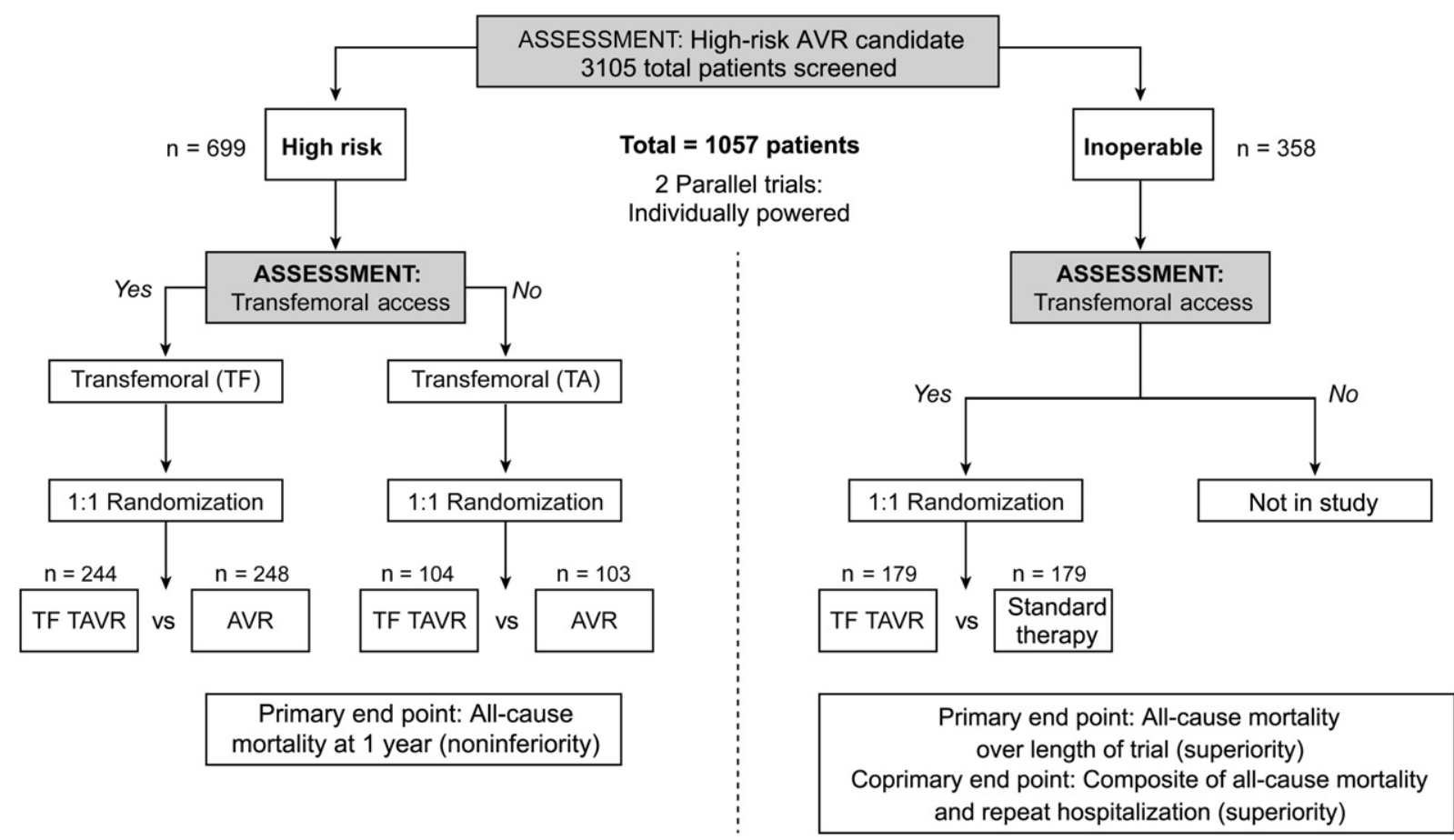

FIGURE 1. PARTNER cohort diagram. PARTNER, Placement of Aortic Transcatheter Valves; AVR, aortic valve replacement; TAVR, transcatheter aortic valve replacement; $T F$, transarterial femoral; $T A$, transapical.

complications with TAVR, less bleeding, and more moderate or severe paravalvular regurgitation (10.5\% at 6 months).

For PARTNER B, ${ }^{2,6} 358$ patients were enrolled, and baseline variables were mostly well balanced. The average STS score was $11.6 \%$, but many patients who were deemed inoperable would not have had a high score-for example, with porcelain aortas $(15.1 \%$ of patients), chest deformity or radiation $(13.1 \%)$, severe chronic obstructive pulmonary disease (COPD, 23.5\%), or severe frailty $(23.1 \%)$-because those comorbidities are not captured completely by the STS scoring.

Of the 179 TAVR patients, 6 did not undergo a successful procedure ( 2 for failed access, 2 for too large an annulus), 2 died during the procedure, 1 had embolization, 2 underwent multiple valve implantations, and 11 died within 30 days $(11 / 173,6.4 \%)$. None had open surgery. Thus, 9 patients $(6 \%)$ did not have a successful valve insertion. Of note, $63.7 \%$ in the control group underwent balloon valvuloplasty within 30 days $(63.7 \%)$ and an additional $20 \%$ underwent balloon valvuloplasty after 30 days. A total of $6.7 \%$ had AVR; $2.8 \%$, left ventricular apex to descending aorta conduit; and $2.2 \%$ underwent TAVR outside the United States. At 30 days after randomization, TAVR mortality was $5.0 \%$ and control was $2.8 \%(P=.61)$, and at 1 year the mortality was $30.7 \%$ for TAVR and $50.7 \%$ for control.
For the primary end point - death or rehospitalizationby Finkelstein-Schoenfeld analysis, TAVR was also superior to control $(P<.001)$. Major strokes at 30 days were $5.0 \%$ versus $1.1 \%(P=.06)$, and at 1 year, $7.8 \%$ versus $3.9 \%(P=.18)$. Moderate to severe paravalvular aortic regurgitation was present in $11.8 \%$ at 30 days and $10.5 \%$ at 1 year. Moderate or severe central regurgitation was present in $1.3 \%$ at 30 days and $4.2 \%$ at 1 year. Subgroup analysis showed patients with severe mitral valve regurgitation and larger body size (body mass index $[\mathrm{BMI}]>25 \mathrm{~kg} / \mathrm{m}^{2}$ ) tended to benefit more from TAVR. Detailed analysis of patients with unknown causes of death showed most had died in nursing homes or hospice from multiple sources of organ failure, failure to thrive, and general old age and frailty, without a specific cause. Multiple variable analyses showed that, for TAVR, the best independent predictors were STS score and BMI. After TAVR, it is of interest that the effect of differences in the EuroSCORE, ejection fraction and age was largely negated and had no influence on late outcomes.

Two-year data analysis of PARTNER $\mathrm{A}^{1}$ and $\mathrm{B}^{2}$ confirmed the 2 previous reports, but also added further information on late outcomes concerning stroke and paravalvular leaks. In particular, the update of PARTNER A showed an additional 32 TAVR deaths and 25 AVR deaths, with no difference at 2 years $(33.9 \%$ and $35 \%$, respectively, $P=$.78). 
There are 4 concerns regarding paravalvular leaks: stroke, endocarditis, hemolysis, and ongoing heart failure. Stroke or transient ischemic attack occurred in $11.2 \%$ with TAVR versus $6.5 \%$ with $\operatorname{AVR}(P=.05)$ at 2 years, but after the early hazard, this did not change. Of note, there were no repeat TAVRs between 1 and 2 years, and the prevalence of endocarditis was similar between the groups $(1.5 \%$ and $1.0 \%, P=.61)$. No hemolysis was documented for TAVR, and rehospitalization and New York Heart Association classes were similar. Of interest, the multivariable late predictors for deaths (TAVR and AVR) were BMI $(P<.01)$, liver disease $(P=.006)$, STS score $(P=.02)$, and moderate or severe mitral valve regurgitation $(P=$ $.04)$; a higher mean gradient was protective $(P=.02)$. For TAVR alone, the predictors were BMI $(P<.001)$, preoperative creatinine level $(P=.04)$, and prior vascular surgery or stent $(P=.05)$; high mean gradients were protective $(P=.003)$. For AVR, the predictors were STS score $(P=$ $.004)$, liver disease $(P=.02)$, and moderate or severe mitral valve regurgitation $(P=.006)$, and prior coronary artery bypass grafting was protective $(P=.002)$.

Of particular note was the influence of paravalvular regurgitation. ${ }^{1}$ It was moderate in $7.0 \%$ and severe in $1.9 \%$ at 1 year, and at 2 years, the respective values were $6.9 \%$ and $0.9 \%(P<.001$ for both intervals $)$, and it tended to improve over time for TAVR. Paravalvular or total aortic regurgitation after TAVR was associated with worse survival $(P<.001)$, and even mild regurgitation increased mortality. Given the strong influence of mild regurgitation and the difficulty in grading paravalvular regurgitation after TAVR, it is possible that the label "mild" underestimated regurgitation that was likely more severe.

For PARTNER $\mathrm{B},{ }^{2}$ the noteworthy findings at 2 years were a $68 \%$ mortality with conventional medical treatment, $43.3 \%$ for TAVR $(P<.005)$, and crossover after 1 year did not affect results; however, 1-year mortality after TAVR crossover was $10 \%$ compared with $21 \%$ for those who did not receive TAVR and cross over. Of the $82.3 \%$ who had balloon valvuloplasty, there appeared to be an initial 6-month benefit, but a time-dependent covariable analysis failed to show any benefit. The multivariable predictors of poor late survival were lower BMI $(P=.005)$, prior stroke $(P=.01)$, and COPD and oxygen $(P=.03)$. The STS score was a predictor for survival after TAVR $(P=.01)$. Of note, for patients with an STS score of $<5 \%$, after TAVR-usually for radiation heart disease or porcelain aorta-2-year survival was about $80 \%(P=.04)$, and this group benefited the most. Prevalence of strokes for TAVR was higher than after medical treatment at both 1 and 2 years. After 30 days and up to 2 years, 9 strokes occurred with TAVR and 5 with medical treatment, although the influence of balloon valvuloplasty was not examined.

The detailed analysis of stroke after TAVR or AVR in PARTNER A showed that $51 \%$ of strokes were procedure related, and $38 \%$ occurred within 2 days: $43 \%$ of patients ultimately died. ${ }^{3}$ Analysis by procedure showed that for neurologic events (1.4\% at 30 days), open AVR had the lowest risk followed by TF-TAVR $(4.6 \%$ at 30 days; $P=$ $.05)$, then group non-TF, with no difference between TATAVR and open AVR. Overall, for both TAVR and open AVR, the early multivariable predictors of neurologic events were TAVR versus open AVR, preprocedure cerebrovascular disease, and smaller indexed native aortic valve area. The late hazard phase predictors were TAVR versus open AVR, higher New York Heart Association class, stroke within 6 to 12 months, non-TF-TAVR group, with less risk with previous percutaneous coronary intervention, and COPD.

Cost analysis for PARTNER B showed a mean cost of $\$ 78,542$ and a median length of hospital stay of 10.1 days, 8.6 days postprocedural. ${ }^{4}$ One-year postprocedure cost was $\$ 18,074$ and, based on an estimated 3.1-year survival, total life cost after the trial during the first year was $\$ 43,664$, for a grand total of $\$ 140,280$ per patient, which turns out to be $\$ 50,212$ per life-year gained. The cost of the valve for the calculations was $\$ 30,000$ per device, but the current cost is $\$ 32,500$ per device. For qualityadjusted survival gain, the cost was $\$ 61,889$ per year.

Health-related quality of life analysis in PARTNER B patients showed that Kansas City Cardiomyopathy Questionnaire score improvement was better at 30 days with TAVR than control $(P<.001)$, with an even greater benefit at 6 months and 12 months $(P<.001) .{ }^{21}$ Physical and mental scores (SF-12 [Short Form-12] General Health Survey) were also better $(P<.001)$ with TAVR than in nonoperated controls.

The Center for Medicare and Medicaid Services conducted a detailed review of the PARTNER trial data based on the reported results, and also there has been FDA analysis and assessment by the Belgian and British (NICE) Health Authorities. The Center for Medicare and Medicaid Services also recommended draft requirements for a program to be reimbursed for carrying out TAVR. For previous PARTNER TAVR research sites, the requirements were $>50$ AVRs per year, 10 with an STS score $>6,>2$ cardiac surgeons, $>400$ catheterizations $/ 150$ percutaneous interventions per year, and $>15$ endovascular or thoracic endovascular aneurysm repair procedures per year. For continued reimbursement, requirements were ongoing involvement in trials or postapproval studies, $>30$ TAVR procedures and $>20 /$ year, 30-day mortality $<15 \%$, neurologic events $<15 \%, 90 \%$ follow-up, and $>60 \%$ 1-year survival for inoperable patients. Surgeons are also required to be qualified, to have performed $>100$ AVRs, including $>10$ high risk or $>25 /$ year, and $>20$ in the year prior to approval. Under the requirements of National Coverage Determination payments for Medicare Parts A or B, payments may not occur for procedures that are not reasonable or 
necessary for diagnosis, treatment, or improvement in function. The Center for Medicare and Medicaid Services asked 2 questions: (1) Is the evidence adequate to conclude that TAVR improves health outcomes of Medicare beneficiaries with severe symptomatic aortic stenosis who are not candidates for surgical AVR [PARTNER B]? The Center for Medicare and Medicaid Services concluded that "the evidence is not adequate to conclude that TAVR generally improves health outcomes." TAVR, however, may improve health outcomes "in carefully monitored clinical studies performed by expert multi-disciplinary heart teams" and monitored in the STS/American College of Cardiology Transcatheter Valve Technology Registry. ${ }^{24}$ (2) Is the evidence adequate for high surgical risk candidates for AVR [PARTNER A]? The Center for Medicare and Medicaid Services determined that "for the highly selected patients in Cohort A, TAVR provided no mortality benefit but significant risk of harms. We believe that Medicare coverage for this patient population should be restricted only to clinical trials rather than registries."

Results of TA-AVR continued access showed that experience had grown from an average of 7.4 cases per site in PARTNER A to 38.4 cases per site. Continued access patients were older $(P=.007)$, STS score stayed the same, prior coronary interventions increased to $85.6 \%(P=.01$; $50 \%$ coronary artery bypass grafting, $47 \%$ percutaneous coronary intervention $[P=.002]$, and $30.5 \%$ balloon aortic valvuloplasty $[P=.0002])$. Thirty-day and 1 -year mortality were $8.2 \%$ and $23.6 \%$, versus PARTNER ATA-AVR $8.7 \%$ and $29 \%$, and $7.6 \%$ and $25 \%$ for AVR. The most marked improvement was the decline in stroke prevalence to $2.0 \%$, versus $7.0 \%$ with TA-AVR and $5.5 \%$ with AVR. Mortality and prevalence of stroke were lower for the newer sites, indicating the benefit of sharing experience between sites, and also an improvement in techniques.

Of the 1801 Cleveland Clinic patients reviewed up to December 2010, $214(12 \%)$ underwent TAVR with a mortality of $1 \%$; in 2011, 105 underwent TAVR: 34 TA-AVRs with no deaths and 71 TF-AVRs with 1 death.

\section{DISCUSSION}

Remarkably good survival has been achieved with the new balloon expandable aortic valve devices. There is a price accompanying the procedure, however ${ }^{22,23}-$ namely, neurologic events and groin injury-although the PARTNER trial data (A vs B and TA-TAVR continued access) suggest that these risks are diminishing. Indeed, the newer filter devices will likely reduce the risk of stroke further. Furthermore, the newer percutaneous closure devices and improved femoral artery closure methods have reduced the risk of bleeding. The transaortic approach also has a minimal risk of bleeding-related complications.

The extent of use and adoption of these devices will clearly depend on FDA approval for high-risk surgical patients, and also the Center for Medicare and Medicaid Services coverage. This will become better clarified during the next few months. Furthermore, the PARTNER A II trial is evaluating the device in lower risk patients (STS score $>4 \%$ ) and will help define the influence of less severe comorbidity on outcomes. The limitations of the trial are the selective nature of the patients treated with the device; in our hands, only $12 \%$ of patients were enrolled. Nevertheless, rarely in cardiovascular medicine, and certainly for valve surgery, has such a well-controlled and funded trial been performed.

\section{References}

1. Kodali SK, Williams MR, Smith CR, Svensson LG, Webb JG, Makkar RR, et al Two-year outcomes after transcatheter or surgical aortic-valve replacement: the PARTNER trial investigators. N Engl J Med. 2012 March 26. [Epub ahead of print]

2. Makkar RR, Fontana GP, Jilaihawi H, Kapadia S, Pichard AD, Douglas PS, et al Transcatheter aortic-valve replacement for inoperable severe aortic stenosis: the PARTNER trial investigators. NEngl J Med. 2012 March 26. [Epub ahead of print].

3. Miller DC, Blackstone EH, Mack MJ, Svensson LG, Kodali SK, Kapadia S, et al. Transcatheter (TAVR) vs surgical (AVR) aortic valve replacement: occurrence, hazard, risk factors, and consequences of neurologic events in the PARTNER trial: the PARTNER trial investigators and patients: the PARTNER Stroke Substudy Writing Group and Executive Committee. J Thorac Cardiovasc Surg. 2012;143:832-43.e13.

4. Reynolds MR, Magnuson EA, Lei Y, Leon MB, Smith CR, Svensson LG, et al. Placement of aortic transcatheter valves (PARTNER) investigators: healthrelated quality of life after transcatheter aortic valve replacement in inoperable patients with severe aortic stenosis. Circulation. 2011;124:1964-72.

5. Smith CR, Leon MB, Mack MJ, Miller DC, Moses JW, Svensson LG, et al. Transcatheter vs surgical aortic-valve replacement in high-risk patients: the PARTNER trial investigators. N Engl J Med. 2011;364:2187-98.

6. Leon MB, Smith CR, Mack M, Miller DC, Moses JW, Svensson LG, et al. Transcatheter aortic-valve implantation for aortic stenosis in patients who cannot undergo surgery: the PARTNER trial investigators. N Engl J Med. 2010;363:1597-607.

7. Bonow RO, Carabello BA, Chatterjee K, de Leon AC Jr, Faxon DP, Freed MD, et al. 2008 Focused update incorporated into the ACC/AHA 2006 guidelines for the management of patients with valvular heart disease: a report of the American College of Cardiology/American Heart Association Task Force on Practice Guidelines (Writing Committee to Revise the 1988 Guidelines for the Management of Patients With Valvular Heart Disease): endorsed by the Society of Cardiovascular Anesthesiologists, Society for Cardiovascular Angiography and Interventions, and Society of Thoracic Surgeons. Circulation. 2008;118:e523-661.

8. O'Brien SM, Shahian DM, Filardo G, Ferraris VA, Haan CK, Rich JB, et al. The Society of Thoracic Surgeons 2008 cardiac surgery risk models: part 2: isolated valve surgery. Ann Thorac Surg. 2009;88:S23-42.

9. Lung B, Cachier A, Baron G, Messika-Zeitoun D, Delahaye F, Tornos P, et al. Decision-making in elderly patients with severe aortic stenosis: why are so many denied surgery? Eur Heart J. 2005;26:2714-20.

10. Dewey TM, Brown D, Ryan WH, Herbert MA, Prince SL, Mack MJ. Reliability of risk algorithms in predicting early and late operative outcomes in high-risk patients undergoing aortic valve replacement. J Thorac Cardiovasc Surg. 2008;135:180-7.

11. Cribier A, Eltchaninoff H, Bash A, Borenstein N, Tron C, Bauer F, et al. Percutaneous transcatheter implantation of an aortic valve prosthesis for calcific aortic stenosis: first human case description. Circulation. 2002;106:3006-8

12. Cribier A, Eltchaninoff H, Tron C, Bauer F, Agatiello C, Sebagh L, et al. Early experience with percutaneous transcatheter implantation of heart valve prosthesis for the treatment of end-stage inoperable patients with calcific aortic stenosis. J Am Coll Cardiol. 2004;43:698-703.

13. Cribier A, Eltchaninoff H, Tron C, Bauer F, Agatiello C, Nercolini D, et al. Treatment of calcific aortic stenosis with the percutaneous heart valve: midterm follow-up from the initial feasibility studies: the French experience. $J$ Am Coll Cardiol. 2006;47:1214-23.

14. Webb JG, Chandavimol M, Thompson CR, Ricci DR, Carere RG, Munt BI, et al Percutaneous aortic valve implantation retrograde from the femoral artery. Circulation. 2006;113:842-50.

15. Walther T, Simon P, Dewey T, Wimmer-Greinecker G, Falk V, Kasimir MT, et al. Transapical minimally invasive aortic valve implantation: multicenter experience. Circulation. 2007;116:I-240-5. 
16. Svensson LG, Dewey T, Kapadia S, Roselli EE, Stewart A, Williams M, et al. United States feasibility study of transcatheter insertion of a stented aortic valve by the left ventricular apex. Ann Thorac Surg. 2008;86: 46-55.

17. Piazza N, Grube E, Gerckens U, den Heijer P, Linke A, Luha O, et al. Procedural and 30-day outcomes following transcatheter aortic valve implantation using the third generation (18 Fr) CoreValve revalving system: results from the multicentre, expanded evaluation registry 1-year following CE mark approval. Eurointervention. 2008;4:242-9.

18. Thomas M, Schymik G, Walther T, Himbert D, Lefèvre T, Treede H, et al. Thirtyday results of the SAPIEN Aortic Bioprosthesis European Outcome (SOURCE) registry. Circulation. 2010;122:62-9.

19. Akins CW, Miller DC, Turina MI, Kouchoukos NT, Blackstone EH, Grunkemeier GL, et al. Guidelines for reporting mortality and morbidity after cardiac valve interventions. J Thorac Cardiovasc Surg. 2008;135: 732-8.

20. Finkelstein DM, Schoenfeld DA. Combining mortality and longitudinal measures in clinical trials. Stat Med. 1999;18:1341-54

21. Reynolds MR, Magnuson EA, Wang K, Lei Y, Vilain K, Walczak J, et al. Costeffectiveness of transcatheter aortic valve replacement compared with standard care among inoperable patients with severe aortic stenosis: results from the placement of aortic transcatheter valves (PARTNER) trial (cohort B): PARTNER investigators. Circulation. 2012;125:1102-9.

22. Svensson LG. Percutaneous aortic valves: effective in inoperable patients, what price in high-risk patients? J Thorac Cardiovasc Surg. 2010;140:S10-3.

23. Schaff HV. Transcatheter aortic-valve implantation: at what price? N Engl J Med. 2011;364:2256-8.

24. Center for Medicare and Medicaid Services. Available at: http://www.cms.gov. 